TURIZAM

Volume 17 , Issue 2

45-59 (2013)

\title{
Spa-Wellness Center as Part of the Hotel Facility
}

\author{
Milica Rančić, Jovanka Popov-Raljić, Lazar Pavić* \\ Received: February 2013 | Accepted: Aprile 2013
}

\begin{abstract}
Over the last decades "wellness spa" industry has experienced a boom around the world. The word "Wellness" has been formed by merging two words: "Well Being" + "fitness", and appeared in the thirties of the last century in the United States. The primary objective of this movement is an ancient philosophy, according to which there's no fulfilled life without the assent of the physical and mental, also physical and spiritual. Hotel guests, today more than ever, want higher quality offer for their money. This means that wellness is today a very important criterion by which customers select hotels. For this reason it is necessary to pay great attention to the planning, design and construction of this part of the hotel facility. The subject of this paper is wellness and spa centers as part of the hotel facility. The task is to investigate and analyze elements of this space, to determine spatial areas of wellness center, as well as their relationships and spatial organization, in order to reach the goal - getting useful guidelines for planning quality wellness center. To all of this could be achieved, we must first go back to distant history where dating back the beginnings of wellness.
\end{abstract}

Keywords: hotel industry, wellness, hotel development, fitting and equipment

\section{Introduction}

The word wellness is usually used to indicate a healthy balance of mind, body and spirit that results in an overall feeling of well-being. This expression is tied for alternative medicine, and it is first used by Halbert L. Dunn in mid 5O's of $20^{\text {th }}$ century. The modern concept of wellness did not, however, become popular until 1970. The term is defined by the National Institutes of Wellness in Wisconsin as "an active process of becoming aware and making choices toward a more successful existence". This is in line with the changes that the focus is away from prevention of illness and approaching to prevent human health. In other words, wellness is to assess the state of health that emphasizes the entire being and its ongoing development. Wellness can be described as "constant, conscious pursuit of living to its fullest potential" (Zimmer, 2OIO).

\footnotetext{
* University of Novi Sad, Faculty of Sciences, Department of geography, tourism and hotel management, Trg Dositeja Obradovića 3, 21000 Novi Sad, Serbia; Corresponding author: milicarancic@hotmail.com
} 
Alternative approaches to wellness are often denoted using two different terms: "health and wellness" and "wellness programs". Wellness programs offer alternative medical techniques to improve health. Whether these techniques actually improve physical health is controversial and the subject of much debate. James Randi and James Randi Foundation are the honest critics of this alternative concept of a new era of health. Wellness often includes many health related disciplines, such as therapy with natural products.

Wellness, as part of the luxury needs, can readily be found in affluent societies because it involves dealing with the body, after the basic needs for food, shelter and medical care base are already accomplished. Many of the activities applied in wellness, in fact, aimed at controlling the side effects of enrichment, such as obesity and inactivity. Wellness roots can be found in $19^{\text {th }}$ century, when the middle class in the industrialized world found time and resources for different forms of self-improvement.

Wellness, as defined by the Foundation of Wellness, considers prevention without drugs, which can not be eliminated health problems, but they can be prevented. Wellness focuses on minimizing the effects of the three dimensions of stress: physical stress (which causes irritation to the nervous system), chemical stress (which causes toxicity of the body) and mental stress (which can trigger hormonal changes, mainly in the adrenal glands).

It may be noted that the definition of wellness vary depending on who promote it. These wellness promoters try to ensure a healthier population and a higher quality of life. It is the pursuit of a healthy, balanced lifestyle. Wellness as an alternative concept generally means more than the absence of disease - an optimal state of health. Supporters of the program believe that many factors contribute to wellness: living in a clean environment, eating organic food, doing regular physical exercise, balance career, family, relationships, and the development of faith (Cherry, 2006).

Participating in wellness programs aims to make people feel better and have more energy. These programs allow individuals to take greater responsibility for their health behavior. Private wellness programs are often enrolled to improve fitness, smoking cessation, and the regulation of body weight.

Wellness programs in the workplace are recognized by a growing number of companies. They are part of the health and security of the company. These programs are designed to improve employee morale, loyalty and productivity.

\section{Historical overview of wellness spa-tourism}

Visitors to modern wellness centers are often not aware of the origin of the old treatment used during their stay. Indian practice dates back to $5000^{\text {th }}$ BC. History of spa and medical tourism is connected with yoga and Ayurvedic medicine. Egyptian women used cosmetics (similar modern) 5000 years ago. The earliest known writings on Chinese medicine date back to the year IOOO BC. But Chinese medicine is still seen as something "new" and exotic. Sumerians were still around year 4000 BC built the earliest known spa complexes, which were built around hot springs.

The earliest records about the treatment of medicinal water date from the year $\mathrm{I} \mathrm{OO}^{\text {th }}$ BC. Hippocrates, a physician and philosopher of the Hellenistic era, said: “... the water is still, after all, the best medicine." Oldest cultural evidence had founded swimming in the river valleys of the Indus, where there is an ancient tradition of bathing in the waters of the channel, and bathrooms pools. Ancient Greek civilization $7 \mathrm{OO}^{\text {th }} \mathrm{BC}$ introduces cold water 
in which warriors swim and Persians 600-300 BC used steam baths and mud. Jews had a cleansing ritual dip in the Dead Sea water years 200 BC and Thais (Siamese people) are practicing massage round year IOO BC.

The Roman Empire left a legacy of incredible spas, demonstrated by examples: Bath, United Kingdom (year 76 BC), Spa, Belgium (year IOo BC), Baden Baden, Germany (year 2I). Roman baths were popular among the elite of that time, and were used for medical purposes, but also as centers of social life of rich classes (Košić, 2OII).

During the Ottoman Empire, Turkish baths were built (year 800), and the kings of Great Britain used the bathroom during the Crusades I2OO. Saunas have started as early as year IOooth, along the Baltic coast of Finland. The characteristic of Finnish sauna is the stove, which was heated stones, and the walls are benched for visitors siting. Finnish sauna is a basic type of sauna with the high-temperature (from 70 to IOO degrees Celsius) and relatively low humidity (5 to $20 \%$ ). In the $4^{\text {th }}$ century the bathrooms in Bormio, Italy, appears for the first shower, as well as the discovery of the hot springs in central Europe (eg Karlovy Vary, Czech Republic).

The sixteenth century is marked by the European Renaissance, which testifies to the growing interest in balneotherapy (water treatment) as well as the practice of medicine (especially in Italy, where they were known in Abano sulfurous springs and mud baths in the harbor and Kaldieru). The first European spa directory (European Spa Directory) is printed in the newspaper Venice in I553, where it is described more than 200 spas. The seventeenth century was characterized by the discovery of mineral and chemical properties of water, and the effects are gradually coming to the fore, and the effects of water temperature are also investigated. Late $\mathrm{I} 8^{\text {th }}$ century, realized the benefits of sea water, and it was the beginning of thalassotherapy, which was especially popular in France. Early $19^{\text {th }}$ century developed modern forms of massage (especially in Sweden). In Germany was opened first modern hydrotherapy spa, providing medical services and air, cold water and food treatments. This trend has begun to start in Europe and America. In I880 father Sebastian Kneip started practicing hydrotherapy for the poor. At the end of the $19^{\text {th }}$ century, the guides are promoted worldwide medical air and sun treatments, including resort spas in the Caribbean and in North Africa as well as Europe and Russia. The enthusiasm for health and exercise among high class increased and highly active tourism became popular (www.srbija-banje.com).

Many European historic spa towns were built around healing springs between $4_{4}^{\text {th }}$ and $16^{\text {th }}$ century, as Vichy in France. By the end of the $18^{\text {th }}$ century, spa treatments and bathing were also developed. Hydrotherapy has been studied as another form of medicine because of the belief in the curative waters. Numerous mountain climate centers have been built in the Alps, the Carpathians and around the Mediterranean. However, gradually the motivation for coming to the spas changed from medical treatment to fulfilling leisure and relaxation, so many spas have begun to open casinos and dance halls and other entertainment facilities (theaters, parks, libraries...). The first international spa congress was organized in Budapest (the capital city of the world congress) 1937. After World War II, the importance of spa centers in Western Europe began to stagnate. However, the communist Central and Eastern Europe and the Soviet Union, spa has entered a new phase of development where the treatment is mainly sponsored by the unions in their specialized departments. The big change came in the appearance of spas. The dominant feature of their physical planning became a trade union resorts, hotels and sanatoriums. Rehabilitation for people becoming "combines healing" based on mineral water, climate and other local natural resources. Boarding facilities were usually large properties with pools of mineral water and equipment to treat 
with storage part, a dining room and a conference room. Miscellaneous services were almost neglected (Košić, 2OII, Blešić et al, 2OO9).

\section{Examples of traditional architecture related to spa-welness activities}

\section{Roman Thermae}

In Roman society there were a place where all equaly were able to deal with body. They were the thermae (thermos = hot), that is public baths in which approach was not limited to anyone. The first baths were built in Rome in $3^{\text {rd }}$ century BC but they were simple and were called Balneae. Structure of Roman baths (example Figure I) would be as follows:

- communication rooms

- locker rooms

- rooms with heated air

- bathroom

- hot tub

- cold baths

- saunas

- swimming pools and

- massage rooms.

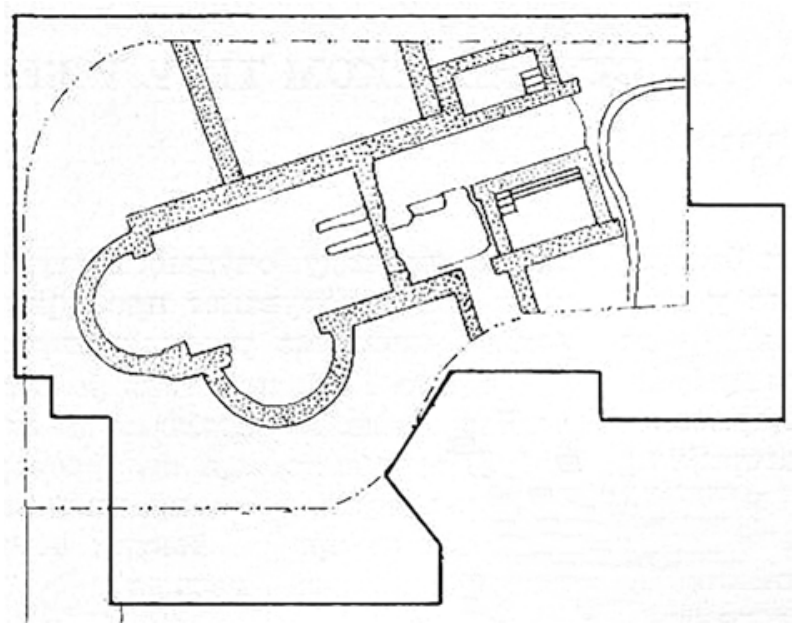

Figure 1. Plan of Roman baths found during work on the Student Square in Belgrade Source: dragoljub1938.wordpress.com

Heating of water has been done through a special system of floor heating (hypocaust). Heated air was turned into canals that pass through walls to specific places in the pools and the water warmed. Rooms are heated by the hot air circulated through a special lining in the cavity walls and the floors. 


\section{Turkish hamams}

The culture and construction of swimming baths Turks have tooked from the Romans and the Byzantines. Baths were built around religious sites as one of the most important buildings (example Figure 2). Religion has caused the separation of men and women in the ritual bath.

The structure of Turkish hamam:

- locker rooms

- cabins

- fountain

- warm rooms

- hot room

- central flagstone

- private angular cells and

- tub with faucets (Košić, 2OII).

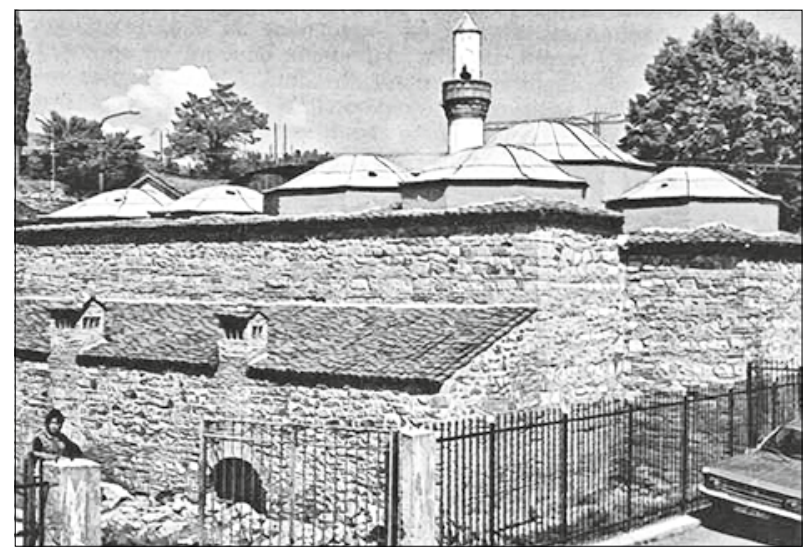

Figure 2. Isabey Isakovic Hammam in Novi Pazar

Source: www.novipazar.rs

\section{Spa-wellness center as a part of hotel facility}

Guests' expectations in spa-wellness hotels increase through time (Blešić et al, 2OII). There are increasingly development of recreational facilities in hotels, the outdoor pools in motels, large wellness centers in the city hotels, to spacious golf course and tennis courts, marinas, and ski resorts in resorts. Although research shows that guests use the pool less, they however expect hotel to have the recreation area, often offering a swimming pool. It is essential that the contractor fits these facilities (example Figure 3). Specialization in hotel industry today becomes more and more harmonized with motives for visiting some destination and that is the reason why many hoteliers today try to equip their objects according to guests' expectacitions (Kosar, 2007).

Contrary to the low use, some hotel operators rather than minimize, expand recreational facilities and very aggressively marketed them, in addition to providing accommodation. In a very competitive market, this is one area where a hotel might have an advantage over other hotels. For example, developers of city hotels may include a wellness center that com- 


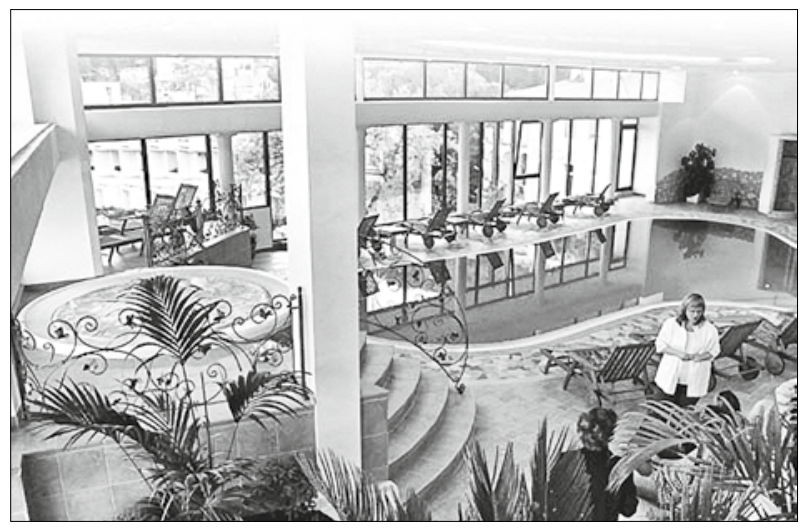

Figure 3. Wellness center Opatija

Source: www. lifeclass-opatija.com

plements the other hotel, business-oriented, the suburb that is projected at an indoor swimming pool and other facilities (Čerović, 2008).

Different types of recreational activities are often found in different types of hotels. Generally, small hotels and motels, mid-range, which greatly attract travelers who care about the price, and include a little bit more than just outdoor swimming pool, playgrounds and a small fitness center. Larger hotels, especially those oriented toward business people are increasingly adding a wellness center, where you can find the following amenities: gym, sauna, and perhaps room for playing squash.

Resorts and other types of accommodation which provide services for guests who are staying longer, and hotels in remote areas where land taxes are less, have additional outdoor recreational facilities.

It is anticipated that the spa centers will have to pay more attention to create certain parts of the building that are more experiential, where it is possible to "self treatment". These areas may include steam rooms with aromatherapy, organic sauna, color therapy air, specialty hot showers, relaxation and meditation, aquamassege tables, foot massagers, and even certain parts with challenging and entertaining games. Development of spa centers must adapt to trends where the spa centers are places of socialization, and equipment must be adapted for at least two or three people at a time. Versatility and flexibility in the design of creation are essential to meet the requirements of various market segments (Penner et al, 2OI2).

An important component of the recreational facilities of a hotel is its wellness center, which is in many hotels become more primary content then the pool. The focus of the wellness center is a combination of gym equipment (equipment used in gyms) and specialized content, such as steam bath, Jacuzzi and sauna. Larger complexes in the wellness center include beauty salons, multipurpose rooms for aerobics etc.

Items that should be taken into account during the planning stage are:

- Position: Wellness centre should be positioned so that guests can get directly to the center, rather than going through the hotel lobby.

- Service Facilities: reception, hairdresser, lockers to leave belongings, showers and toilets, exercise room, sauna, steam room and Jacuzzi, massage room and lounge.

- Space: plan complex that will have a controlling position and lounge in a conspicuous place, with a dedicated private space, whether it is shared (a practice) or for individual use (sauna) (Čerović, 2008). 


\section{Spatial structure of spa-wellness centre}

In developing the conceptual design for the construction of a wellness spa and its equipment in small and large hotels, one must determine what to put in the center. In addition to the basic elements such as an entryway to the dressing room, toilets and showers, some with sauna, Turkish bath, then, space cooling (cold showers, ice machine, cold water pool), jacuz$\mathrm{zi}$, a relaxation area and to serve different beverages, to be determined in accordance with the capacity of the hotel, it is very important to predict in advance whether it will be wellness only for hotel guests or will be open to other visitors. Another issue is how to sell it, that is, whether the price will be included in room price or not. However the most important are following:

The entrance to the reception area is a place where the customer has the first direct contact with the spa personnel. There is acquired first, stronger and more concrete impression of the facility in which it came. Reception, in addition to receiving and informational, has security function. It consists of a desk, behind which there is all the technical equipment needed for the functioning of the reception and the staff is responsible for receiving, customer service, information and greeting guests. Very often in the reception department beside reception there is a rest area with armchairs.

Wardrobe (locker room) is a very important part of the wellness spa center, especially in terms of the security. Usually contains lockers for each guest individually. Men's and women's locker rooms are separate, and there can be located toilets.

Showers and toilets are an essential part of any wellness center. Usually they are located next to the dressing room (also separated male from female).

Fitobar is a part of spa center, which is used for serving food and drinks. Here guests can refresh themselves after training or treatment. Usually provides energy services and healthy drinks and low-calorie meals in the form of biscuits, fruit and so.

Massage rooms should have a temperature from 24 to 25 degrees Celsius. Massage bed should not be less than 2 meters long, $0.7 \mathrm{~m}$ wide and $70-80 \mathrm{~cm}$ high, depending on the hight of masseurs. The upper surface is covered with a spongy rubber material from which is suitable for washing. In addition, the bed should be equipped with several roller pads which should provide ideal rest position. Bed should be covered with the clean sheet.

Water facilities are mainly pools of different sizes. They can be for children and adults, with hot or cold, fresh or salt water. Also, the water facilities are hot tubs and Whirlpool. This type of pool is often named Jacuzzi, which is wrong, because Jacuzzi is name of the company that was among the first started producing whirlpools or "spa pool", as they call them in the predominantly English-speaking. Whirlpools are small pools with air underwater massage, filtration, heating, (and frequently) disinfect water system. Most models are fitted with the underwater spotlights as standard. Some models are large enough to swim with the use of the device for the current swimming and then we talk about the spa pool (spa-pool).

Finnish sauna is a room designed as a place for dry or wet body heating. Modern sauna originated from the Finnish sauna. Sauna room is paneled in wood, because inside there should be no part of the subject or of some other material, especially from metal. Heat capacity and thermal conductivity are different in metal and wood, and at a high temperature in the sauna metal parts can cause burns to large scale. In addition to the sauna walls are built of wooden benches that can be in one or more levels are used for sitting and lying. When there are multiple levels, staying at a different level allows to the patient using different degrees of heating of air. Sauna has no windows, but the door is opening that is glazed 
with a thermostable glass to be able to see and control what is happening inside the sauna, what is the health status of people who are inside. In addition to the sauna is a small pool or showers with cold water. There must be a room with cold drinks, and holiday refreshments. Capacity of sauna depends on its size. Small, family sauna can accomodate four to five people, and in hotels can accommodate ten or more persons (www.aquaplan.rs).

Russian bath is kind of sauna made of wood where temberatura reaches IOO degrees Celsius. It provides a special pleasure vapors with the scent of medicinal herbs. In a separate wooden liner saves water with various medicinal herbs, which slowly pours on the burning rocks in the bowels of the furnace where the volcanic rocks. Thereby there is expanding steam, with special, delicate and intoxicating fragrance.

Turkish bath or hamam comes from the Middle East, and the room intended for the hammam is mainly decorated in oriental style, to gain an impression of their culture. It is a kind of sauna bathing in steam, where the air is saturated with moisture, and the temperature goes up to $5 \mathrm{O}^{\circ} \mathrm{C}$. Steam consists of dry and steam filled chamber, and in addition owns and pays for relaxation and massage. Due to the temperature of $5 \mathrm{O}^{\circ} \mathrm{C}$ and humidity of $100 \%$ compared to the sauna, which is $80^{\circ} \mathrm{C}$ and humidity from $2 \%$ to $30 \%$, Turkish bath is more comfortable stay. The hammam has heated floors, walls and benches, and does not create heavy and foggy vapor, visibility has fallen, though the humidity reaches almost IOO\%.

Kneipp Bath is most famous water treatment, whose creator is called the father of wellness. German Catholic priest-physician Sebastian Kneipp (I82I-I897) developed this type of therapy with water. The simplest is sitting Kneipp bathroom with two ceramic bowls for dipping feet of water with different temperatures. With a hot water faucet guest can optionally regulate water and harmonize with his strength. After a while, he can move from hot into cold water.

Tepidarium is a Roman invention for total relaxation, and socializing. It is anatomically shaped with heated stone beds, which are perfect for tense back muscles. The walls of tepidarium are made of stone, lined with tiles or marble. The air humidity is medium. The barely exceeds the body temperature and feel very comfortable to the body. Blood vessels expand and that in remote parts of the body improves blood flow and the body is heated without sweating. The heat that commes out of the walls, floor and deck acts on the vegetative nervous system.

Ice cave (ice room) - more hotels and wellness centers have ice making device used to cool and refresh the body. Cooling this way not only feel nice, but has a healing effect. This drastic change in temperature shrinks dilated blood vessels, which improves blood circulation in the body and gives blood vessel elasticity. Ice is used after using the sauna or steam bath. This is the final phase of the "hot bath", and is a much better hygiene solution than traditional immersion in a cold pool.

Shower of experience is tropical rain and cold fog showering system, with fragrances and colors. Properly designed shower must be an integral part of overall wellness centar (www.parnakupatila.com).

\section{Pool as the largest water facility}

Although the size of pools varies, most hotel operators require from contractor to include a swimming pool. Pool needs to be separated from the public part of the hotel, so guests, who were dressed in bathing suits, do not have to go through the lobby. Other key items include the following: 
- Positioning: pool should be set up so that guests can get to it from their rooms by elevator or stairs;

- Orientation: pool should be set to be, if possible, exposed to sun throughout the day;

- Size: It should be large enough for swimming and sunbathing, but not less than 6xI2 $\mathrm{m}$ with at least $3 \mathrm{~m}$ of space for deck chairs on all sides;

- Extra Facilities: It should be provided toilets, lockers for leaving things, stand for the issuance of towels, snack bar and vending machines for drinks, a room with equipment and space for additional equipment and deck chairs;

- Security: there should be no jumping board, ensure non-slip surface, water deep marks, notice of the rules of conduct at the pool;

- Children's swimming pool / Jacuzzi pool: additional pools should be near the main pool;

- Indoor pool: pool should be designed with a glass roof to provide solar transmittance and easier ventilation (Penner et al, 2OI2).

Pool is a part of the overall comfort rather than direct income-generating space. It represents a high investment and high current cost, but the activities around the pool can make a profit (selling food, selling drinks, ice cream, etc.) and should build them whenever possible. Pool should be located so that it is the focal point of interest for restaurants, bars, guest rooms. The negative effects are noise, interference (irritation at night, etc.). It is necessary to take measures of shielding, isolating and safety-lighting measures at night. Swimming pools can be internal, external, mixed with fresh or sea water, with or without a sauna, irregular-shaped to fit different in landscape or square for multipurpose use. Covering high investment and the economy must be investigated previously.

Common or stardandni pools are 25 XI2.5 m (multiple purposes with stands), and the smaller hotels and other hospitality establishments have pools measuring I5 x 8 or $9 \mathrm{~h} 4.5 \mathrm{~m}$. The bottom is usually angled, shallower portion is about I $\mathrm{m}$ and deeper is $\mathrm{I} .8 \mathrm{~m}$ deep. Pool should be protected from cold winds, facing the sun, protected from the visual surrounding roads and buildings, from dust and leaves... The pool area can be grouped as a unique space, recreational facilities, sauna, solarium, gym, massage and courts (tennis, squash and the like). Pool surroundings have certain standards. Surface around the pool should be paved (as noted above at least 3 - $5 \mathrm{~m}$ wide) for sunbathing, with efficient drainage canals, not slippery, easy to clean (debris, oil, sun, etc.) no bumps, of durable material, acids, detergents, moisture and drying, high temperature, cold, shock and scratch resistant. The most commonly used are stone tiles, marble, mosaics, ceramics and more. Around the pool and on the steps there are holders, low voltage (I2 V) airtight recessed alcoves in the wall or on the bottom of the pool. Other recreational and sporting facilities and equipment with covered and outdoor pools may include squash courts, tennis courts, a gymnastics hall, a sauna, a solarium. Some hotels in the peak season hiring animators. These activities can be carried out in the same places for sports and recreational activities (swimming, for example, at night).

Water in the pool must be continuously recycled for filtering, heating and sterilization. Common standards for filtering is 0.3 to $0.5 \mu \mathrm{m}$, I.O ppm of residual chlorine, for heating $0.5^{\circ} \mathrm{C}$ warming per hour, for water circulation I-I2, for temperature $22-3 \mathrm{O}^{\circ} \mathrm{C}$. Arrangements should be easily accessible, corrosion resistant and reliable. Other requirements apply to floating debris cleared, clean sediment, water meter, drainage basins, toilets, changing rooms, showers. Pool may be provided with special blanket to prevent energy loss (at night or in bad weather) and to prevent falling debris. Safety equipment includes life vests, bell hooks 
for drawing, instructions and warnings, phone, first-aid. Complex equipment includes fountains, aeration spray, waterfalls, underwater viewing, creating artificial waves, space for spectators (Božović, 2009).

\section{The space structure of spa-wellness centers}

In developing and equipping each new spa-welness, it is necessary, first of all, to define the concept - whether it be a hotel, medical, club or urban wellness. When designing the space it should be used more materials and architectural design from surroundings, as well as the smells, sounds and images from nature. To treatment creation it is important to fit into environment. A beautiful panoramic view may be a goal and guests will certainly hard forget it. For the project, it is important that the space is well designed, and at the same time comply with the necessary requirements and financial capability of the investor.

In medium-sized hotels with 60-70 rooms wellness area can be made on a total area of 60 to $80 \mathrm{~m}^{2}$. Of course, apart from the basic facilities (Finnish sauna, hot bath, at least one cold shower and hot shower, a place to rest and changing rooms, lockers to store valuables, and at least two showers to shower before entering into the wellness and toilet), an investor may opt for the pool, which, in relation to the size of the remaining space can be $5 \mathrm{x}$ IO $\mathrm{m}$. In this case, it is sufficient total area of $\mathrm{I} 3 \mathrm{O} \mathrm{m}^{2}$. Many come in the wellness center for beauty treatments. Surely it would be advisable to add another $20-30 \mathrm{~m}^{2}$ in order to find a place for 2 - 3 treatment rooms.

When developing wellness spa in small hotel, with about 20 double rooms (4O beds), it is advisable to cancel the pool because of high maintenance costs, and the size is concerned. It is also enough $70-80 \mathrm{~m}^{2}$, in which were included massage rooms. Particular attention should be paid to small hotels, which often have a need for a wellness center, but the problem size of the available space. What is important for small hotels is the ability to incorporate in the sauna rooms, massage bathtubs, or that can be placed on the terrace. In a small hotel it is a great additional content. Sauna and Whirlpool can also be installed into luxury apartments. Today's sauna manufacturers have to offer different combinations that are ideal for small spaces. It is a combination of the Finnish sauna, steam bath and shower, which occupies $2.8 \mathrm{~m}^{2}$ and combined shower and steam bath area - $\mathrm{I} .7 \mathrm{~m}^{2}$ (www.spawellness.izlog.org).

The following is an example of a small wellness spa in small city hotel and an example of a wellness spa complex in a resort (Figure 4).

An example of a wellness center in Figure 4 is the typical small town hotel that does not have too much space to waste. To the left of the entrance is a reception area with waiting room in which there are small tables with chairs and reception. There is also fitobar located in reception to provide food and beverage services. To the right of the entrance are locker rooms. However, what is notable is that no separation of "clean" and "dirty" ways. Guests then enter the locker room the same way, which later countinuing to the pool and spa area.

At the beginning of the main wellness space, to the left, there is the massage area which is divided into two parts by screen wall (it has two massage tables). Spa has been singled out as a separate entity, which took into account the current space with the following contents: Kneipp, showers, warm benches, sauna, Jacuzzi. Exercise equipment is grouped on a separate space.

It can be concluded that this is a spa center with a simple organization of space, but at the same done by the book, with a few minor flaws, such as the above error in the crossing of "dirty" and "clean" ways. 


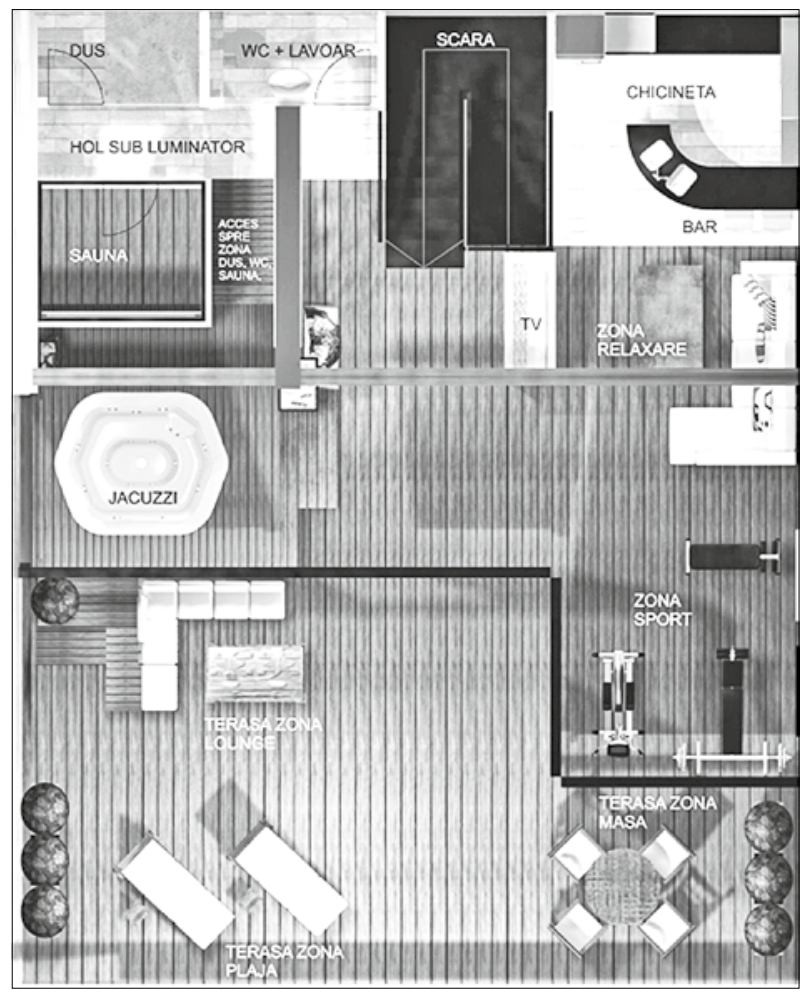

Figure 4. Wellness center plan for a small town hotel

Source: www.georgiacristea.com

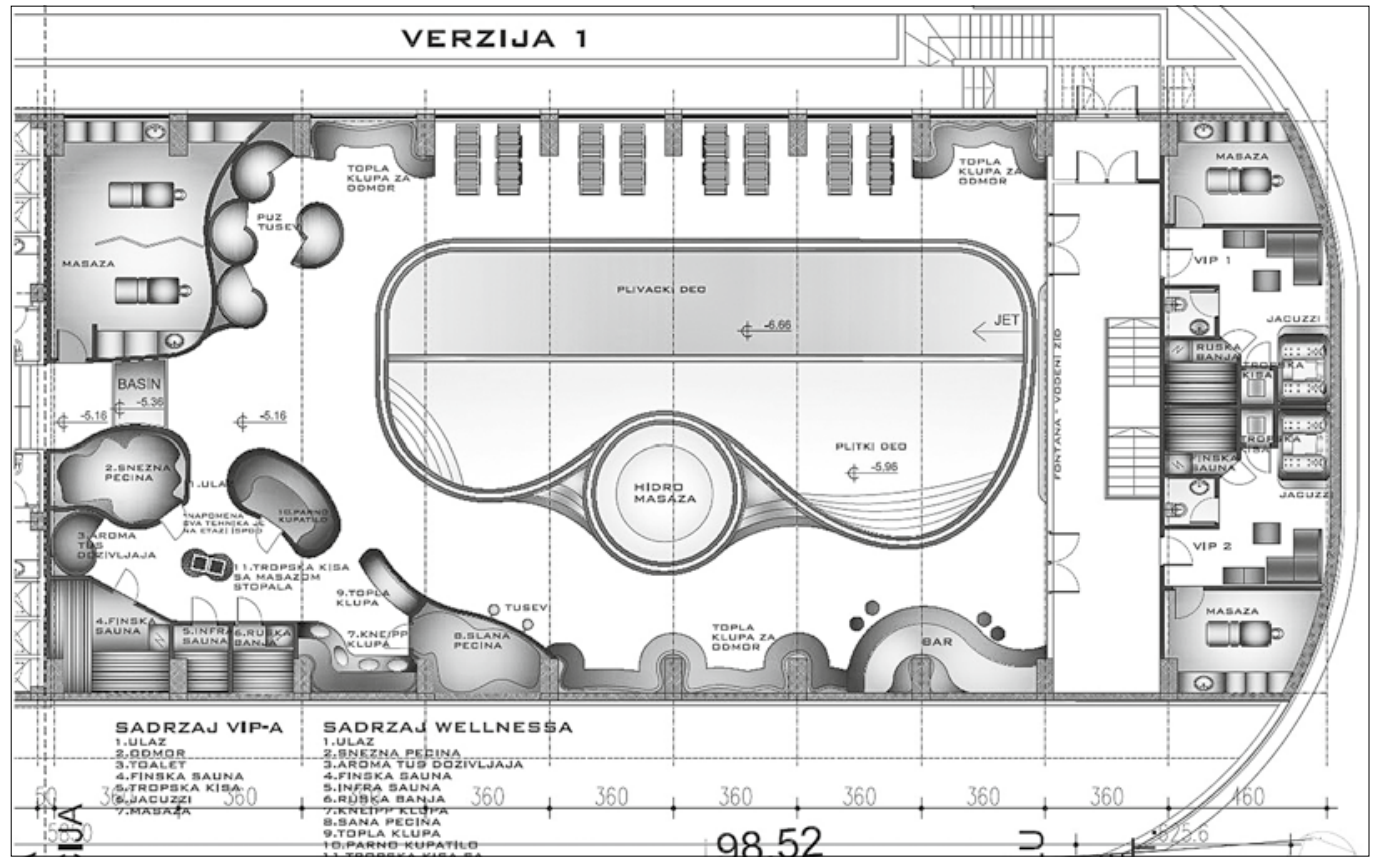

Figure 5. Wellness complex plan

Source: www.parnakupatila.com 
The first characteristic, noticed in the example in Figure 5, is a separate part for VIP guests, and therefore this spa has two entrances. VIP area is also divided into two symmetrical parts, with almost the same content, with the only difference that on the one side is Finnish sauna and Russian bath is on the other. The entrance to the VIP area leads directly into a rest area, from which one can enter in massage room, while on the other side is the toilet. Sauna, Whirlpool tub and tropical rain cabins are concentrated in the same area. Suppose that the quality of service in the VIP section is at a higher level. Next to it, there is a hallway with two passages to the spacious wellness area, which is surrounded by a wall in the form of fountains and water walls. Large water area includes a swimming pool in the middle (divided into swimming and shallow pool), a hot tub and all the other facilities that are arranged around the pool. On both sides of the pool are set warm benches and chairs and one hand showers. In the immediate vicinity of one of the aforementioned two entrances there is a bar. Spa unit is spatially separated and includes the following elements: snow cave, aroma shower experience, Finnish sauna, infrared sauna, Russian bath, Kneipp, salt room, steam bath, tropical rain with a foot massage. In contrast to these units, there is space for a massage, which is divided by a screen into two parts.

What can be seen as a minus or not visibly marked is the entrance of reception area. However, what can be singled out as plus is feet washing tub in front of the entrance to the spa area, which proves the separation between "dirty" and "clean" ways.

\section{Spa-wellness center conceptual plan proposal for a typical medium-sized hotel}

After analysis of the entire spatial entities of wellness center, their relationships, as well as all existing content, one can reach certain conclusions useful for functional architectural design and project plan of a quality wellness center.

Large main entrance to the wellness center leads to the lobby (entrance hall), where can be seen two passages, one leading to the reception and one on the opposite side leads to fitobar. Near the entrance space there is a storage room or closet. The following areas are men's and women's locker rooms, each with a separate toilet and shower.

Next wellness center area contains a fitness center, massage room and solarium. The above content need to be placed close to the entrance to the locker room, because there are guests who do not want to go into the spa area (they use other treatments, a gym, massages and solarium). A massage room should have screen (movable) walls between the massage tables so that each guest during the massage had privacy. Besides the massage room there is personnel room.

From fitness room through pantry one can enter Finnish sauna. It is important that Finnish sauna is located near fitness room, because for many users training programs include the use of sauna. In addition to the Finnish sauna is a Russian bath, and next to these two is situated small pool with cold water as well as ice cave. Namely, after the use of the Finnish sauna or Russian bath recommended treatment is cold water or a short stay in an ice cave, and even more alternate is transitioning from warm to cold environment and vice versa. For this reason it is very important that the above facilities are concentrated next to each other. The next room is the tepidarium or room with warm chairs, while on the opposite side there is Kneipp and Turkish bath.

The large hall, locker room and guest space leads to water facilities. Along it are located tropical rain showers, and at the bottom of the hall and in front of the area with water facilities are feet washing tubs, which are very important for hygiene. The wellness center 


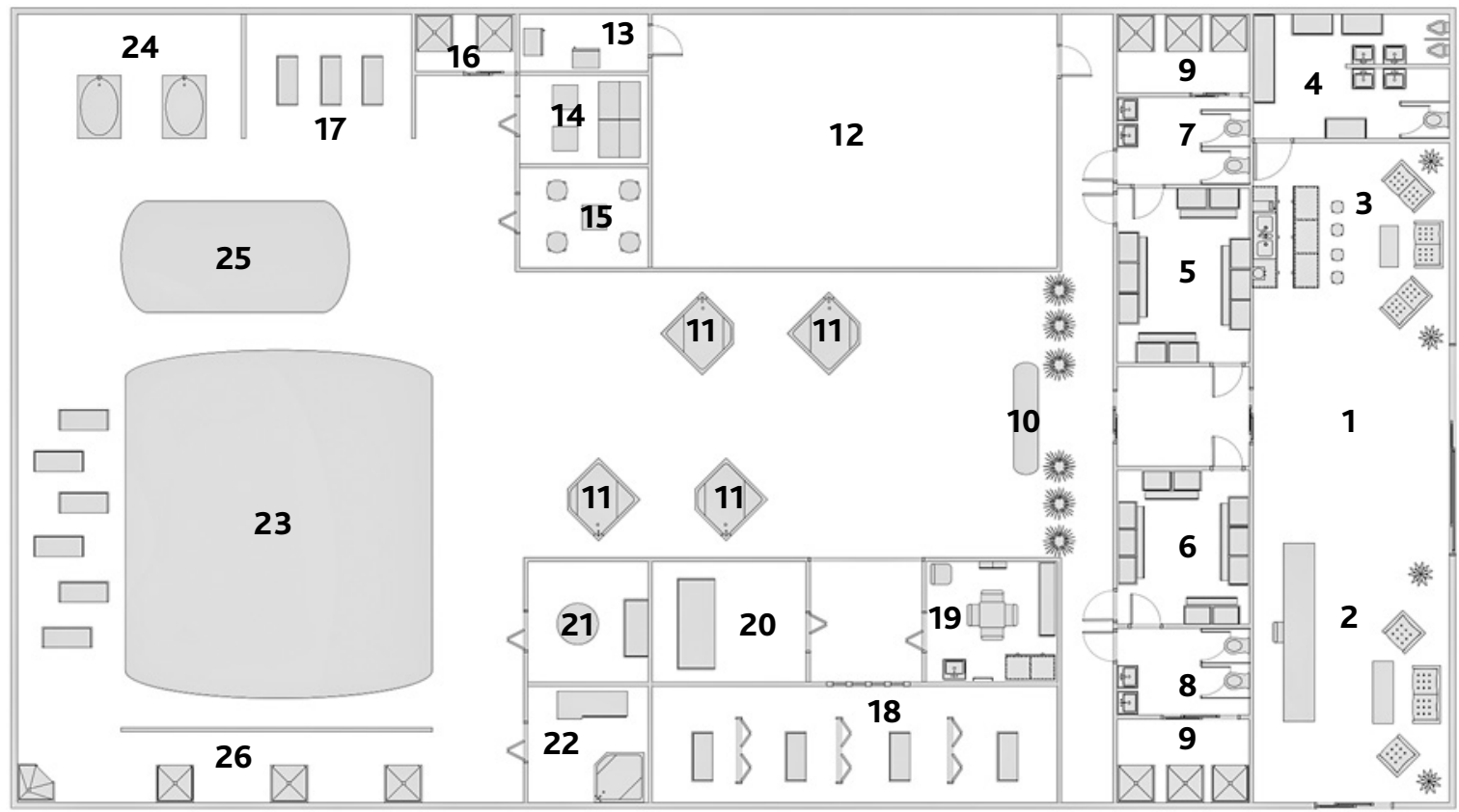

Figure 6. Conceptual design of the spatial organization of spa-welness center (idea by authors)
1. Lobby
8. Women's toilet
15. Russian bath
22. Kneipp bath
2. Reception
9. Shower cabins
16. Ice cave
23. Swimming pool
3. Fitobar
10. Feet washing tub
17. Tepidarium
24. Hot tubs
4. Closet
11. Tropical rain shovers
18. Massage room
25. Hot pool
5. Men's licker room
12. Fitness gym
19. Personnel room
26. Jet shower
6. Women's locker room
13. Equipment store
20. Solarium
14. Finnish sauna
21. Turkish bath

water facilities include: a large swimming pool, a hot water pool and a spa pool, and next to them is a jet shower. It is important that there is direct communication between the entrance and pools area, in case guests want to use only pools without going into the other spa facilities.

Therefore, the idea was to separate areas for guests with different requirements, as well as a very important separation of clean and dirty ways which in some respects can be successfully solved by installing bathtubs, feet washing tubs before entering the pool or spa area.

In Table I it is given SWOT analysis of Serbian wellness market as a contribution to this conceptual plan proposal. 
Table 1. SWOT analysis of Serbian wellness market

\begin{tabular}{|c|c|}
\hline Strengths & Weaknesess \\
\hline $\begin{array}{l}\text { - Lower prices compared with competitors } \\
\text { - No seasonal preferencies } \\
\text { - Quality of natural resources (water, air) } \\
\text { - Intensive development of wellness tourism in Serbia com- } \\
\text { pared with past periods }\end{array}$ & $\begin{array}{l}\text { - Low service quality } \\
\text { - Lack of complementary services } \\
\text { - Inadequate promotion of native supply in wellness tourism } \\
\text { - Non-profesional personnel in spa/wellness centres } \\
\text { - Lack of strategies and investitions for wellness tourism } \\
\text { - Levelopment } \\
\text { - Lack of cooperation with other sector of tourism } \\
\text { - Spsolete and lack of modern equipment } \\
\text { pliance with logical sequence of using services }\end{array}$ \\
\hline Opportunities & Threats \\
\hline $\begin{array}{l}\text { - Lower prices with possibilities to attract turisti from eco- } \\
\text { nomically developed European contries (German, Scandina- } \\
\text { vian countres, Russia, Italy...) } \\
\text { - Changes in a way of living (less free time, more stress, older } \\
\text { people,...) } \\
\text { - Higher number of spa and wellness tourists } \\
\text { - Spa and wellness culture became mainstream } \\
\text { - Perception of hotel guest which consider that wellness } \\
\text { centre is mandatory part of hotel object } \\
\text { - Acceptance to contemporary trends in architecture during } \\
\text { equipping wellness centres }\end{array}$ & $\begin{array}{l}\text { - Competitors from near environment with more developed } \\
\text { wellness tourism (Hungary, Slovenia) } \\
\text { - Market mismatch of capacities to expectications of contem- } \\
\text { - Image of Serbia as a sanatorium and destination for static } \\
\text { vacation } \\
\text { - Still bigger interests for } 35 \text { tourism than for wellness } \\
\text { tourism } \\
\text { - Absence of foreign investitors for construction and moderni- } \\
\text { zation of wellness centres }\end{array}$ \\
\hline
\end{tabular}

Source: Authors

\section{Conclusion}

History of wellness centers started as early as $5000 \mathrm{BC}$, than gradually developed, as can be seen from the example of Roman baths and Turkish hammams. Today's wellness facilities are at a very high level, so the terms wellness and spa gained more significance.

Wellness Center has become an inseparable part of any more luxurious hotels. If the hotel building is larger and more luxurious, the spatial structure of wellness center is more complex. There are many parts of the wellness center, which must be well organized spatially, to take place efficient service delivery. Analysis of existing wellness centers shows us the good and bad architectural solution. On this basis, and applying knowledge about wellness, we come up with ideas how to make a good one wellness center with a spatial arrangement that allows a very efficient implementation of therapies and other services.

Current situation in Serbia about wellness tourism and equipment of wellness centres is not at the appropriate level. Progress can be seen in a fact that in a past few years it is recorded more intensive development of wellness tourism compared with the previous period. Unfortunately, compared with contemporary trends and developed wellness tourism countries, Serbia lags behind both in architectural and equipment aspect. The opportunity for future development can be found in better strategy and provoding financial resources through projects and investing those resources in "clever" and economical construction and equipping of contemporary wellness centres. In this way, Serbia would have excellent combination of traditional spa sanatoriums and contemporary wellness centres, which would in addition with competitive prices could creat the image of real wellness destination.

Wellness, as weel as its equipment, are develop and modernized for years, all in accordance with the development of techniques, technologies, materials and resources, but with 
one very important factor - user/guest requirements. Adapting to them and the resources available, the creators of these properties had always tried and continues to make a good facility with the possibility of even better service. It seems that the wellness and spa industry today are at a very high level, but the current development shows that in the future we can expect more innovation in this field.

\section{References}

Blešić, I., Ivkov-Džigurski, A., Stankov, U., Stamenković, I., Bradić, M. (2OII). Research of exspected and percived service quality in hotel management. Revista de turism - Journal of tourism II, 6-I4.

Blešić, I., Romelić, J., Bradić, M., (2009). Application of modified SERVQUAL model in assessing the quality of hotel services on the example of West-Moravian spa zone. Proceedings of the Geographic Institute "Jovan Cvijić, SANU, 59(I), 93-IIO.

Bogdanović, M., (2OII). Trends in wellness tourism, University Singidunum, Departmant for postgraduate studies, Belgrade.

Božović, R. (2009). Construction of hospitality objects, Seminar work, Faculty of Sciences, Novi Sad.

Cherry, R. (2006). Can You Pray Your Pounds Away?. Vegetarian Times, 80-83.

Čerović, S., (2008). Designing and construction of hotels, University Singidunum, Belgrade. Kosar, LJ., (2007). Adapting of hotel industry to modern forms of tourism. Journal Turizam II, IO-I3.

Košić, K., (2OII). Spa, medical and wellness tourism, Script, Faculty of Sciences, Novi Sad. Penner, R., Adams, L., Robson, S., (2004). Hotel Design, Planing and Development. Routledge, 22I-227.

Romelić, J., (2008). Tourism Regions of Serbia, Faculty of Sciences, Novi Sad.

Zimmer, B., (2OIO). Wellness. The New York Times, I23/2OOO, II.

www.dragoljubi938.wordpress.com

www.srbija-banje.com

www.spawellness.izlog.org

www.spawellness.izlog.org

www.parnakupatila.com/sr/sadrzaj/I28/projektovanje

www.parnakupatila.com

www.georgiacristea.com/2009/o5/attic-spa-and-sport-center.html

www.aquaplan.rs

www.lifeclass-opatija.com 